\title{
Academic Writing Needs of TESOL Postgraduate Students in the Saudi Context
}

\author{
Bayan Ibrahim AlHashemi \\ University of Jeddah, Jeddah \\ E-mail: Bayanalhashemi141@gmail.com \\ Muneerah Shuraim AlSubaeie \\ King Abdulaziz University, Jeddah \\ E-mail: Muneerahalshuraim@gmail.com \\ Nadia Ahmad Shukri \\ King Abdulaziz University, Jeddah \\ E-mail: ndshukri@gmail.com
}

$\begin{array}{ll}\text { Received: November 21, } 2017 & \text { Accepted: December 4, } 2017 \quad \text { Published: December 5, } 2017 \\ \text { doi:10.5296/ijele.v5i2.12235 } & \text { URL: https://doi.org/10.5296/ijele.v5i2.12235 }\end{array}$

\begin{abstract}
Data from previous academic literature reveals that Saudi postgraduate students face a great deal of challenges in academic writing. Some of these challenges are related to the choice of terminology, planning skills, outlining and some other ones. Such data call for significant curriculum developments in postgraduate programs. However, at the heart of any curriculum design is the deliberate analysis of students' lacks, needs and wants. Once these items are determined, curriculum designers and teachers are required to set clear and relevant learning objectives and chose appropriate teaching materials and means of assessment (Otilia, 2015). Using a five-point Likert scale, the current study aims at investigating postgraduate students' academic writing needs at the English Language Institute (ELI) of King Abdul-Aziz University. This investigation involves the written tasks students are required to perform, the learning sources they use, and their overall writing needs as perceived by the students themselves as well as by their teachers. The results of the study reveal that among the various academic writing needs of postgraduate students, the use of correct punctuation, spelling,
\end{abstract}


proper writing mechanics and plagiarism-free content should were given the highest priority as perceived by their teachers. Students, on the other hand, indicated that the overall academic writing ability, proper representation of ideas, use of proper mechanical conventions and choice of field-related words are among the skills they need the most in order to succeed. Based on these results, a group of recommendations and implications were drawn and directed to the Postgraduate Unit.

Keywords: Needs-analysis, academic writing, postgraduate students, King Abdul-Aziz University, Saudi context

\section{Introduction}

It has long been assumed that at the heart of curriculum design is the analysis of students' needs and wants. According to Nation \& Macalister (2009), the importance of this part of the curriculum design comes from the fact that this analysis is directly addressing the goals and content of a course and is carried out to ensure that a given curriculum is beneficial and relevant to students. The results of the needs analysis, as Otilia (2015) asserts, give teachers an overview of what language skills learners need to acquire, their deficiencies and lacks. Once students' needs are determined, curriculum designers and teachers are required to meet those needs by setting clear objectives for the course and choosing appropriate teaching materials.

Academic writing is a requirement for all university-related spheres and in most disciplines and faculties. Maher (2013), pointed out that the use of academic writing skills determines how students' academic performance is more likely going to be. That is because one way or another, most assignments in the Humanities and Language departments are related to literacy, especially to writing skills. Due to the fact that the starting point of academic writing skills is the situation and learners, (Hamp-Lyons, 2001, cited in Huang, 2010), this study intends to analyze TESOL postgraduate students' academic writing needs from teachers' and students' perspectives.

\subsection{Background of the Study}

The current study was undertaken at the English Language Institute (ELI) of King Abdul-Aziz University in Jeddah, Saudi Arabia. The ELI offers a master's degree program in TESOL. According to the description of MA in TESOL Program (2014) available on ELI-KAU website, this program aims at facilitating post-graduate students' professional knowledge of Teaching English to Speakers of Other Languages. Furthermore, it aims at developing students' practical and research skills in the field of English Language Teaching. In order for students to enroll in this program, they are required to have a bachelor's degree in either one of the following majors: English Language and Linguistics, English Language and Literature, or Translation. In addition, the score has to be no less than six in IELTS or its other equivalents. 


\subsection{Research Questions}

The current study aims at answering the following research questions:

- What academic writing skills do graduate students in TESOL perceive as important for satisfactory completion of the courses in their programs?

- What academic writing skills do instructors perceive as important for satisfactory completion of courses in TESOL at the graduate level?

\section{Literature Review}

\subsection{Academic Writing}

English-language proficiency, according to Roessingh (2006), involves skills of two types. The first one is called basic interpersonal communicative skills (BICS) whereas the other one is called cognitive academic language proficiency (CALP). Since its initial appearance, the difference between BICS and CALP has theatrically and practically impacted teaching and assessment processes related to learning (Cummins, 2008). CALP or academic English includes the features of English required for success in educational and academic advancement. According to Scarcella, 2003, this variety of English is dynamic and complex in the sense that it involves various psychological, cognitive, linguistic, and sociocultural processes. Moreover, it involves knowledge of reading, speaking and listening, but most importantly it requires mastery of the writing system.

Generally speaking, the complexity of the writing system has been reported to be high among Arab learners. This complexity has been attributed to many factors including how Arab learners have been taught English throughout their school years, the effects of first language writing skills, anxiety, and intercultural differences between L1 and L2 (Shukri, 2014). Previous research on the difficulties faced by Saudi postgraduate students revealed that academic writing is significantly challenging for ESL students. For example, in a study conducted by Al Fadda (2013), it has been found that postgraduate students face a great deal of difficulties when differentiating between spoken and written language, making an outline, drafting and many other important skills.

Academic writing does not only occur at the linguistic level; it has many other spheres and aspects. According to Fukao and Fujii (2001, cited in Ankawi, 2015), 'academic writing requires students to have the ability integrate skills which include gathering information, paraphrasing and organizing resources, organizing ideas in a logical order, editing, and finally proofreading' (p.8-9). As pointed out by Al Fadda (2013), in order for students to write academically, a number of skills must be mastered. For example, students must be able to re-use information for their own advantages such as when paraphrasing or summarizing a paper. In addition, students' ability to find, assess, and synthesize ideas and texts to develop their own voice is another key to success in academic writing.

Many studies have investigated the needs of post-graduate students when writing academic 
papers. Although some researchers go against setting a specific format for any piece of academic writing claiming that it hinders students' creativity (Matsuda \& Tardy, 2007), other studies concluded that students see the opposite. For example, in a case study conducted by $\mathrm{Li}$ (2007), a doctoral student acknowledged his need to be trained on how to conduct a proper research or paper. This student in the study justified his need for such training by mentioning that most postgraduate students are required to publish some of their work before graduation.

When viewing postgraduate students' academic writing needs as perceived by teachers, three elements are constantly distinguished as the most important and recurrent aspects of academic writing: the choice of vocabulary and grammar, citation and cohesion. As to the choice of vocabulary, some teachers believe that teaching students general academic vocabulary is not that much useful due to the fact that each discipline has its own set of words and structures (Hyland \& Tse, 2007). However, when it comes to grammar, Coxhead (2011) pointed out that a proper academic paper should be written in proper English, following the rules of punctuation, tense and all other textual elements. Furthermore, he also indicated that is essential for academic writers to use proper grammar in order to deliver the message intended appropriately and concisely. Moving to another aspect of academic writing, coherence has been ranked as an extremely important factor and achieving it in writing is not very easy (Ghasemi, 2013); because every word, every sentence and every paragraph needs to contribute to the general message of the paper (Jones, 2007). For this reason, it constitutes a challenge for post-graduate students. One way of overcoming this challenge, as recommended by the student in the study conducted by ( $\mathrm{Li}, 2007)$ is to make an outline before writing. According to him, making an outline before writing helps in generating clearer ideas and well-structured texts. Another essential element of academic writing as indicated by teachers is the implementation of citation. Instructors in previous studies indicated that there is a need from the part of the students to cite their work properly and to avoid plagiarism by all its means (Phakiti \& Li, 2011).

\subsection{Needs Analysis}

Hutchinson and Waters (1987, cited in Nation \& Macalister, 2009) divided students' needs into necessities, lacks and wants. When it comes to necessities, like in the case of academic writing skills necessary for academic success, ways of gathering data according to Nation \& Macalister (2009) vary from using questionnaires and conducting interviews to analyzing students' written papers and tests. Some of the previous studies conducted on students' needs are the following:

1. Studies that used surveys as the main tool for gathering data on students' academic writing needs (AKCAOĞLU, 2011 and Carson, 1994, Huang, 2010).

2. Studies that followed the use of questionnaires with semi-structured interviews (Phakiti, 2012).

3. Studies that investigated language-learning needs through self-reported tools and interviews (Chen, 2010 and Buckingham, 2008).

4. Studies that explored students' needs in writing pedagogy using ethnographic methods as 
observations (Molle \& Prior, 2008).

Nevertheless, Akcaoglu in 2011, asserted that the generalizability feature could not exist when it comes to students' needs. Moreover, he claimed that the needs analysis is context-dependent and should account for environmental factors such as linguistic culture or the context of the institution. To the best of the searchers' knowledge, this study is of importance because it constitutes one of the fewest studies that analyze students' academic writing needs' at the postgraduate level in the Saudi context.

\section{Methodology}

In order to collect the data, an online version of a questionnaire adopted from a study conducted by AKCAOĞLU (2011) was sent to ELI female Postgraduate Unit faculty members and students in spring 2017. To make sure that the study is one representative to the population under study, random sampling was used to give each and every member of the population an equal opportunity to participate. Of the seven potential instructors who received the questionnaire, only four completed it, representing $57 \%$ of the whole population. For the graduate group, only seventeen students completed the questionnaire.

The questionnaire is of five-point Likert scale and has three main parts. The first investigates participants' demographic information, like gender, years of studying or experience, academic status ...etc. The second part aims at examining the writing tasks students are required to produce and the academic resources they use while writing. The third and final part aims at exploring academic writing needs of students from students' and teachers' perspectives. To analyze the data, the Statistical Package for Social Science (SPSS) was used to find standard deviations, frequencies, and mean scores.

\section{Results and Discussion}

Before getting to the part where postgraduate students' academic writing needs are to be identified, a reasonable starting point here is with the academic written tasks students are required to produce as well as the written resources they refer to while writing.

As mentioned before, the first part of the questionnaire investigates the nature and frequency of writing tasks that postgraduate students are expected to produce in their courses. The following table illustrates the order in which the tasks have been placed.

Table 1. Writing Tasks Postgraduate Students Produce

\begin{tabular}{lccc}
\hline & $\mathrm{M}$ & $\mathrm{SD}$ & $\mathrm{N}$ \\
\hline Longer research papers (6 pages or more). & 4.24 & 1.15 & 17 \\
\hline Exams with essay questions. & 3.76 & 1.44 & 17 \\
\hline Critical writing - reflection papers. & 3.59 & 1.06 & 17 \\
\hline Brief summaries of articles read (1-2 pages). & 3.47 & 1.18 & 17 \\
\hline Brief research papers (5 pages or less). & 3.41 & 1.58 & 17 \\
\hline Group writing projects. & 3.41 & 1.54 & 17 \\
\hline Case studies and take home exams. & 1.65 & 1.22 & 17 \\
\hline
\end{tabular}




\section{$\Lambda$ Macrothink}

As shown in Table 1, although the mean value for case studies and take-home exams was found to be the lowest $(\mathrm{M}=1.65, \mathrm{SD}=1.22)$, the mean values for the other tasks were highly close. Longer research papers received the highest score $(M=4.24, S D=1.15)$, followed by the other tasks as shown in Table 2. What is intriguing about this part is that the mean value for group writing projects has been found to be somehow high $(\mathrm{M}=3.41, \mathrm{SD}=1.54)$ unlike the value given to such task in AKCAOĞLU's (2011) study from which the questionnaire has been taken.

Moving to another aspect, the second part of the questionnaire required postgraduate students to indicate how much they need written resources when producing academic tasks. The following table illustrates the order in which these resources have been placed according to the participants' responses.

Table 2. Written Sources Postgraduate Students Refer to

\begin{tabular}{lccc}
\hline & $\mathrm{M}$ & $\mathrm{SD}$ & $\mathrm{N}$ \\
\hline Journal articles published in your area of specialization. & 4.82 & 0.39 & 17 \\
\hline Manuals (i.e., APA manual). & 4.53 & 0.80 & 17 \\
\hline Source books. & 4.12 & 1.11 & 17 \\
\hline Web-based sources. & 4.00 & 0.94 & 17 \\
\hline Spell checks. & 3.94 & 1.14 & 17 \\
\hline Dictionaries. & 3.59 & 1.23 & 17 \\
\hline Grammar books. & 2.00 & 0.87 & 17 \\
\hline
\end{tabular}

As shown in Table 2, it was found that when writing academic tasks, postgraduate students need journal articles published in TESOL $(\mathrm{M}=4.82, \mathrm{SD}=.39)$ and manuals like APA manual $(\mathrm{M}=4.53, \mathrm{SD}=0.80)$ the most. Moreover, source books $(\mathrm{M}=4.12, \mathrm{SD}=1.11)$ and web-based sources $(\mathrm{M}=4.00, \mathrm{SD}=0.94)$ are also commonly needed by students. However, the lowest mean score is recorded to grammar books as a writing guide $(\mathrm{M}=2.00, \mathrm{SD}=$ $0.87)$.

\subsection{Question1}

To answer this question, students were given fourteen items and they were required to determine how much support they need with each one. On a scale of 1-5, with 1 being "no need" and 5 being "very high," students were asked to rate each of the fourteen elements based on how much they are needed for academic writing success. The following table shows these fourteen elements in order based on students' responses.

Table 3. Descriptive Statistics of the Academic Writing Needs from Students' Perspectives

\begin{tabular}{lccc}
\hline & $\mathrm{M}$ & $\mathrm{SD}$ & $\mathrm{N}$ \\
\hline Overall academic writing ability. & 3.94 & 1.03 & 17 \\
\hline Presenting ideas clearly. & 3.88 & 1.18 & 17 \\
\hline Using proper mechanical conventions (e.g. APA style). & 3.71 & 1.31 & 17 \\
\hline Choosing correct words (field-related terminology). & 3.71 & 0.99 & 17 \\
\hline Having rich vocabulary and expressions. & 3.59 & 1.18 & 17 \\
\hline
\end{tabular}


Developing ideas. 2017, Vol. 5, No. 2

Using proper connections and transitions.

Avoiding plagiarism (how to quote, paraphrase or cite).

Organizing the whole text.

$\begin{array}{lll}3.53 & 1.38 & 17\end{array}$

Using correct punctuation and spelling.

$\begin{array}{lll}3.47 & 1.38 \quad 17\end{array}$

Using proper grammar.

$3.47 \quad 1.46 \quad 17$

Organizing paragraphs

$\begin{array}{lll}3.35 & 1.12 \quad 17\end{array}$

Drawing conclusions.

$\begin{array}{lll}3.35 & 1.73 \quad 17\end{array}$

Preparing an outline before starting writing.

$\begin{array}{lll}3.29 & 1.40 \quad 17\end{array}$

$\begin{array}{lll}3.24 & 1.30 \quad 17\end{array}$

$\begin{array}{lll}3.24 & 1.25 \quad 17\end{array}$

$\begin{array}{lll}3.06 & 1.44 \quad 17\end{array}$

As shown in Table 3, the results suggest that graduate students need support with overall academic writing ability $(\mathrm{M}=3.94, \mathrm{SD}=1.03)$ clear representation of ideas $(\mathrm{M}=3.88, \mathrm{SD}=$ 1.18), using proper mechanical conventions $(\mathrm{M}=3.71, \mathrm{SD}=1.31)$ and choosing field-related words $(\mathrm{M}=3.71, \mathrm{SD}=0.99)$ when performing academic writing tasks. In addition, the results reveal that although the other elements received similar scores, the lowest score was given to preparing an outline before writing $(\mathrm{M}=3.06, \mathrm{SD}=1.44)$.

\subsection{Question 2}

To answer the second question, teachers were given fourteen items and required to determine how much support students need with each one. On a scale of 1-5, with 1 being "no need" and 5 being "very high," students were asked to rate each of the fourteen elements based on how much they are needed for success in academic writing. The following table shows these fourteen elements ordered based on teachers' responses.

Table 4. Descriptive Statistics of the Academic Writing Needs from Teachers' Perspectives

\begin{tabular}{lccc}
\hline & $\mathrm{M}$ & $\mathrm{SD}$ & $\mathrm{N}$ \\
\hline Using correct punctuation and spelling. & 5.00 & 0.00 & 4 \\
\hline Using proper mechanical conventions (e.g. APA style). & 5.00 & 0.00 & 4 \\
\hline Avoiding plagiarism (how to quote, paraphrase or cite). & 5.00 & 0.00 & 4 \\
\hline Choosing correct words (field-related terminology). & 4.75 & 0.50 & 4 \\
\hline Using proper grammar. & 4.75 & 0.50 & 4 \\
\hline Using proper connections and transitions. & 4.75 & 0.50 & 4 \\
\hline Preparing an outline before starting writing. & 4.75 & 0.50 & 4 \\
\hline Having rich vocabulary and expressions. & 4.50 & 0.58 & 4 \\
\hline Developing ideas. & 4.50 & 0.58 & 4 \\
\hline Presenting ideas clearly. & 4.50 & 0.58 & 4 \\
\hline Drawing conclusions. & 4.50 & 0.58 & 4 \\
\hline Overall academic writing ability. & 4.50 & 0.58 & 4 \\
\hline Organizing paragraphs. & 4.25 & 0.50 & 4 \\
\hline Organizing the whole text. & 4.00 & 0.82 & 4 \\
\hline
\end{tabular}

As shown in the table 4, the results suggest that teachers gave a very high priority to using correct punctuation and spelling $(\mathrm{M}=5.00, \mathrm{SD}=0.00)$ using proper mechanical conventions $(\mathrm{M}=5.00, \mathrm{SD}=0.00)$, and avoiding plagiarism $(\mathrm{M}=5.00, \mathrm{SD}=0.00)$. Furthermore, the 
results reveal that all the other elements, including preparing an outline, received very similar values, with organizing the whole text receiving the lowest score $(\mathrm{M}=4.00, \mathrm{SD}=0.82)$.

From the preceding description of results, it is clear that the teachers' perspectives regarding postgraduate students' needs differ slightly from students' perspectives. From the teachers' perspectives, the highest priority is given to correct punctuation and spelling, followed by proper writing mechanics and avoidance of plagiarism. Such emphasis on citation and punctuation is supported by Phakiti \& Li (2011) who indicated that teachers put so much emphasis on plagiarism-related issues when evaluating students' writings. In addition, contrary to Akcaoglu's (2011) claims that the results of one needs analysis cannot be generalized to other contexts where different environmental factors exist, the results of this study were extremely similar to Akcaoglu (2011)'s results.

\section{Conclusion}

This study investigated the academic writing needs of postgraduate students at the English Language Institute (ELI) of King Abdul-Aziz University. The main instrument used to run on this investigation was a five-point Likert scale questionnaire adapted from AKCAOĞLU's (2011) study. Using this questionnaire, students were requested to indicate the written tasks they are required to perform, the sources they use while writing, and their overall writing needs. Furthermore, teachers' perceptions of students' academic writing needs were also added to the picture in order strengthen the validity of results. It is worth mentioning, however, that since this study only used a questionnaire, there is a need for further studies that employee follow-up interviews and analysis of students' writings.

\section{Implications and Recommendations}

Based on the results of the study, a group of implications and recommendations can be drawn. In order to fulfill TESOL postgraduate students' academic writing needs, the Postgraduate Unit at the ELI is recommended to offer its students bridging workshops or courses to improve their academic writing skills. Such courses should cover: TESOL-related vocabulary, proper grammar and mechanical conventions use, and the overall academic writing skills that were mentioned previously. Furthermore, according to Jones in (2007), such courses and workshops should take into consideration raising students' awareness of the importance of cohesion and avoidance of plagiarism.

On the research level, it would be beneficial for future studies to conduct follow-up interviews with both teachers and students in order to get a deeper understanding of what students' actually lack and need in specific. Thus, analyzing students' written assignments would be more beneficial when it comes to getting more accurate and objective results regarding students' needs. 


\section{Macrothink}

\section{References}

AKCAOĞLU, M. Ö. (2011). An assessment of academic writing needs of graduate students (Doctoral dissertation, Middle East Technical University).

Ankawi, A. (2015). The academic writing challenges faced by Saudi students studying in New Zealand (Doctoral dissertation, Auckland University of Technology).

Buckingham, L. (2008). Development of English Academic Writing Competence by Turkish Scholars. International Journal of Doctoral Studies, 3.

Chen, C. W. Y. (2010). Graduate students' self-reported perspectives regarding peer feedback and feedback from writing consultants. Asia Pacific Education Review, 11(2), 151-158. https://doi.org/10.1007/s12564-010-9081-5

Coxhead, A. (2011). The Academic Word List 10 Years On: Research and Teaching Implications. TESOL Quarterly, 45(2), 355-362. https://doi.org/10.5054/tq.2011.254528

Cummins, J. (2008). BICS and CALP: Empirical and theoretical status of the distinction. In Encyclopedia of language and education. Springer US.

Fadda, H. A. (2012). Difficulties in academic writing: From the perspective of King Saud University postgraduate students. English Language Teaching, 5(3), 123-130. https://doi.org/10.5539/elt.v5n3p123

Ghasemi, M. (2013). An Investigation into the Use of Cohesive Devices in Second Language Writings. Theory and Practice in Language Studies, 3(9). https://doi.org/10.4304/tpls.3.9.1615-1623

Huang, L.-S. (2010). Seeing eye to eye? The academic writing needs of graduate and undergraduate students from students' and instructors' perspectives. Language Teaching Research, 14(4), 517-539. https://doi.org/10.1177/1362168810375372

Hyland, K., \& Tse, P. (2007). Is There an “Academic Vocabulary"? TESOL Quarterly, 41(2), 235-253. https://doi.org/10.1002/j.1545-7249.2007.tb00058.x

Jones, J. E. (2007). Losing and finding coherence in academic writing. University of Sydney Papers in TESOL, 2(2), 125-148.

Li, Y. (2007). Apprentice Scholarly Writing in a Community of Practice: An Intraview of an NNES Graduate Student Writing a Research Article. TESOL Quarterly, 41(1), 55-79. https://doi.org/10.2307/40264331

M.A. in TESOL Program. (2014). In King Abdul-Aziz University website. Retrieved May 9, 2017, from http://www.kau.edu.sa/GetFile.aspx?id=235692\&fn=MA\%20TESOL\%20English _final\%20PDF.pdf

Maher, C. (2013). Academic writing ability and performance of first year university students in South Africa (Doctoral dissertation).

Matsuda, P. K., \& Tardy, C. M. (2007). Voice in academic writing: The rhetorical 


\section{Macrothink}

construction of author identity in blind manuscript review. English for Specific Purposes, 26(2), 235-249. https://doi.org/10.1016/j.esp.2006.10.001

Molle, D., \& Prior, P. (2008). Multimodal Genre Systems in EAP Writing Pedagogy: Reflecting on a Needs Analysis. Source: TESOL Quarterly, 42(4), 541-566. https://doi.org/10.1002/j.1545-7249.2008.tb00148.x

Nation, I. S. P., \& Macalister, J. (2009). Language curriculum design. Routledge.

Phakiti, A., \& Li, L. (2011). General Academic Difficulties and Reading and Writing Difficulties among Asian ESL Postgraduate Students in TESOL at an Australian University. RELC Journal, 42(3), 227-264. https://doi.org/10.1177/0033688211421417

Roessingh, H. (2005). BICS-CALP: An introduction for some, a review for others. TESL Canada Journal, 23(2), 91-96. Retrieved from http://www.teslcanadajournal.ca/index.php/tesl/article/view/57/57

Scarcella, R. (2003). Academic English: A conceptual framework (Technical Report No. 2003-1). Irvine: University of California Linguistic Minority Research Institute.

Shukri, N. A. (2014). Second Language Writing and Culture: Issues and Challenges from the Saudi Learners' Perspective. Arab World English Journal, 5(3).

\section{Appendix A}

\section{Students' Questionnaire:}

\section{BACKGROUND INFORMATION}

Gender:

Age:

Current Department:

Your English Proficiency Score:

Your Current GPA:

1. Academic Status:

Master's Degree (non-thesis)

Master's Degree (with thesis)

Doctor's Degree (following a non-thesis master's degree)

Doctor's Degree (following a master's degree with thesis)

Integrated Graduate Degree

2. Specify the number of semesters you completed in your current graduate program: 
8. Choose the appropriate item indicating your graduate program stage:

Scientific Preparation

Taking Courses

Writing Thesis

\section{WRITING TASKS}

The following questions pertain to the kinds of writing tasks that you are expected to produce in all of your courses. For each of the following items, indicate how frequently each task might be assigned per semester.

\begin{tabular}{|c|c|c|c|c|c|}
\hline Writing Tasks & 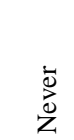 & 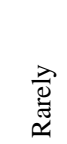 & 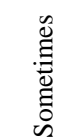 & : & $\frac{n}{\frac{\pi}{3}}$ \\
\hline 1. Brief summaries of articles read (1-2 pages) & 1 & 2 & 3 & 4 & 5 \\
\hline 2. Brief research papers (5 pages or less) & 1 & 2 & 3 & 4 & 5 \\
\hline 3. Longer research papers (6 pages or more) & 1 & 2 & 3 & 4 & 5 \\
\hline 4. Critical writing - reflection papers & 1 & 2 & 3 & 4 & 5 \\
\hline 5. Exams with essay questions & 1 & 2 & 3 & 4 & 5 \\
\hline 6. Group writing projects & 1 & 2 & 3 & 4 & 5 \\
\hline 7. Case studies and take home exams & 1 & 2 & 3 & 4 & 5 \\
\hline 8. Other (Specify) .............................. & 1 & 2 & 3 & 4 & 5 \\
\hline
\end{tabular}

\section{WRITTEN SOURCES}

The following questions pertain to the kind of written sources you may refer to while writing (e.g. assignments, research papers, thesis, and dissertation). For each of the following items, indicate the degree of usefulness for each source by choosing the appropriate number " 1 " indicating "Not useful" and " 5 " indicating "Very useful").

\begin{tabular}{|c|c|c|c|c|c|}
\hline & 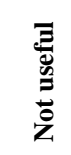 & 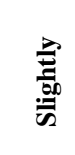 & 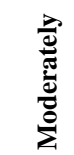 & 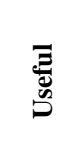 & 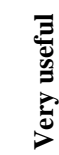 \\
\hline 1. Dictionaries & 1 & 2 & 3 & 4 & 5 \\
\hline 2. Grammar books & 1 & 2 & 3 & 4 & 5 \\
\hline 3. Journal articles published in your area of specialization & 1 & 2 & 3 & 4 & 5 \\
\hline 4. Source books & 1 & 2 & 3 & 4 & 5 \\
\hline
\end{tabular}




\begin{tabular}{|l|l|l|l|l|l|}
\hline 5. Manuals (i.e., APA manual) & 1 & 2 & 3 & 4 & 5 \\
\hline 6. Spell checks & 1 & 2 & 3 & 4 & 5 \\
\hline 7. Web-based sources & 1 & 2 & 3 & 4 & 5 \\
\hline 8. Others .......................... & 1 & 2 & 3 & 4 & 5 \\
\hline
\end{tabular}

\section{ACADEMIC WRITING NEEDS}

For each of the following items, please indicate how much support you need during the process of writing an academic paper (e.g., research papers, critiques, and thesis/dissertation) ("1" indicating "No need" and " 5 " indicating "Very high need").

\begin{tabular}{|c|c|c|c|c|c|}
\hline & $\begin{array}{l}\vec{\Xi} \\
\ddot{\Xi} \\
\ddot{Z}\end{array}$ & בై & $\begin{array}{l}\frac{0}{\pi} \\
\frac{\pi}{\pi} \\
\Sigma\end{array}$ & $\frac{\sqrt{500}}{: \pm 0}$ & 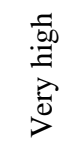 \\
\hline 1. Preparing an outline before starting writing & 1 & 2 & 3 & 4 & 5 \\
\hline 2. Organizing paragraphs & 1 & 2 & 3 & 4 & 5 \\
\hline 3. Organizing the whole text & 1 & 2 & 3 & 4 & 5 \\
\hline 5. Choosing correct words (field-related terminology) & 1 & 2 & 3 & 4 & 5 \\
\hline 6. Using proper grammar & 1 & 2 & 3 & 4 & 5 \\
\hline 7. Using proper connections and transitions & 1 & 2 & 3 & 4 & 5 \\
\hline 8. Using correct punctuation and spelling & 1 & 2 & 3 & 4 & 5 \\
\hline 9. Using proper mechanical conventions (e.g. APA style) & 1 & 2 & 3 & 4 & 5 \\
\hline 10. Developing ideas & 1 & 2 & 3 & 4 & 5 \\
\hline 11. Presenting ideas clearly & 1 & 2 & 3 & 4 & 5 \\
\hline 12. Drawing conclusions & 1 & 2 & 3 & 4 & 5 \\
\hline 13. Avoiding plagiarism (how to quote, paraphrase or cite) & 1 & 2 & 3 & 4 & 5 \\
\hline 14. Overall academic writing ability & 1 & 2 & 3 & 4 & 5 \\
\hline
\end{tabular}

\section{Teachers' Questionnaire:}

\section{BACKGROUND INFORMATION}

Gender:

Current Department:

Years of experience:

Job title: 


\section{ACADEMIC WRITING NEEDS}

For each of the following items, please indicate how much support MA students need during the process of writing an academic paper (e.g., research papers, critiques, and thesis/dissertation) ("1" indicating "No need" and " 5 " indicating "Very high need").

\begin{tabular}{|c|c|c|c|c|c|}
\hline & $\begin{array}{l}\vec{\Xi} \\
\ddot{\Xi} \\
\ddot{0}\end{array}$ & בz & 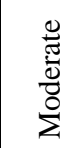 & $\stackrel{500}{90}$ & 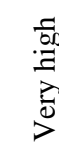 \\
\hline 1. Preparing an outline before starting writing & 1 & 2 & 3 & 4 & 5 \\
\hline 2. Organizing paragraphs & 1 & 2 & 3 & 4 & 5 \\
\hline 3. Organizing the whole text & 1 & 2 & 3 & 4 & 5 \\
\hline 5. Choosing correct words (field-related terminology) & 1 & 2 & 3 & 4 & 5 \\
\hline 6. Using proper grammar & 1 & 2 & 3 & 4 & 5 \\
\hline 7. Using proper connections and transitions & 1 & 2 & 3 & 4 & 5 \\
\hline 8. Using correct punctuation and spelling & 1 & 2 & 3 & 4 & 5 \\
\hline 9. Using proper mechanical conventions (e.g. APA style) & 1 & 2 & 3 & 4 & 5 \\
\hline 10. Developing ideas & 1 & 2 & 3 & 4 & 5 \\
\hline 11. Presenting ideas clearly & 1 & 2 & 3 & 4 & 5 \\
\hline 12. Drawing conclusions & 1 & 2 & 3 & 4 & 5 \\
\hline 13. Avoiding plagiarism (how to quote, paraphrase or cite) & 1 & 2 & 3 & 4 & 5 \\
\hline 14. Overall academic writing ability & 1 & 2 & 3 & 4 & 5 \\
\hline
\end{tabular}

\section{Copyright Disclaimer}

Copyright for this article is retained by the author(s), with first publication rights granted to the journal.

This is an open-access article distributed under the terms and conditions of the Creative Commons Attribution license (http://creativecommons.org/licenses/by/3.0/). 